\section{$\underset{\substack{\text { hommes } \\ \text { \& migrations }}}{ }$}

\section{Hommes \& migrations}

Revue française de référence sur les dynamiques

migratoires

$1304 \mid 2013$

Frontières

\title{
La logique harmonieuse du chao
}

\section{Marie Poinsot}

\section{CpenEdition \\ Journals}

\section{Édition électronique}

URL : http://journals.openedition.org/hommesmigrations/2626

DOI : 10.4000/hommesmigrations.2626

ISSN : 2262-3353

\section{Éditeur}

Musée national de l'histoire de l'immigration

\section{Édition imprimée}

Date de publication : 1 octobre 2013

Pagination : 1

ISBN : 978-2-919040-24-7

ISSN : $1142-852 X$

\section{Référence électronique}

Marie Poinsot, "La logique harmonieuse du chao », Hommes \& migrations [En ligne], 1304 | 2013, mis en ligne le 17 mars 2014, consulté le 22 septembre 2020. URL : http://journals.openedition.org/ hommesmigrations/2626; DOI : https://doi.org/10.4000/hommesmigrations.2626 


\section{LA LOGIQUE HARMONIEUSE DU CHAOS}

par MARIE POINSOT, rédactrice en chef.

En cette fin d'année 2013, le dossier d'Hommes \& Migrations résonne tout particulièrement avec l'actualité internationale, que ce soit l'occupation des Syriens au port de Calais ou les grèves et les manifestations massives des Érythréens à Telaviv, sans oublier les tragédies humanitaires au large de Lampedusa ou entre le Mexique et les États-Unis. L'exploration des frontières est loin de se limiter à l'analyse des tracés géographiques et géopolitiques. Zones de passage et de transit, les frontières relèvent d'institutions dotées de dispositifs de surveillance, de contrôle, de répression, qui obéissent à des politiques d'immigration et à des législations précises. Ainsi, la cartographie des grandes frontières opérantes de nos jours dans le monde sert de cadre d'interprétation aux migrations internationales. Les frontières sont devenues des espaces discursifs surdéterminés et récurrents dans les débats publics pour signifier le poids croissant des logiques sécuritaires, à contre-courant de la mondialisation. Elles servent de cadre à une guerre déclarée aux migrants clandestins en fonction de la crispation des opinions des pays d'accueil sous la menace imaginaire d'une invasion des migrants pauvres. Elles signifient la séparation symbolique avec le reste du monde et la relégation des autres au-delà des murs et des postes de contrôle.

Ce dossier est le résultat d'un appel à contributions lancé par les deux commissaires scientifiques d'une exposition à venir au Musée de l'histoire de l'immigration à l'automne 2015. Les nombreuses propositions reçues révèlent un chantier de recherches en plein renouveau qui interroge les effets multiples des frontières sur les phénomènes migratoires. Dans une vision géopolitique très large, le dossier explore certaines des frontières emblématiques d'aujourd'hui, en mer Méditerranée, entre les ÉtatsUnis et le Mexique, et d'autres espaces où les politiques d'immigration ont des effets sur les modalités de passage et sur les stratégies des candidats à la migration. Il décrit aussi la militarisation et l'externalisation croissantes des frontières mises en place grâce à des accords bi ou multilatéraux de contrôle et de réadmission des sans-papiers.

Mais l'apport du dossier réside également dans le regard que portent les migrants sur ces frontières et sur les pays de destination. Quelles tactiques adoptent-ils pour les traverser ou les contourner? Comment pensent-ils et vivent-ils leurs parcours? Comment traversent-ils un monde clandestin complexe, polymorphe, où l'économie de la frontière fait intervenir un système d'acteurs associant des passeurs souvent mafieux, des militants faisant valoir leurs droits et des policiers? Violence sur soi, marquage du corps, gestes de survie sont le lot quotidien de ceux qui tentent le passage.

Sur les frontières, la légalité et l'illégalité sont comme deuxrives d'unmêmefleuveaucourssinueux, parfois capricieux ou aléatoire. Les frontières suivent désormais "la logique harmonieuse du chaos", pour reprendre l'expression de Michel Agier. Ce dossier décrit comment elles offrent un "espace de spectacle" fortement médiatisé et investi par les États pour délimiter l'altérité.

La rédaction a également confiéà Mogniss Abdallah, de l'agence Im'Média, la coordination d'une série de chroniques permettant de revisiter les trente années de mobilisation collective des générations de l'immigration en France depuis la Marche pour l'égalité et contre le racisme de l'automne 1983. La commémoration de cet événement permet, à sa manière, de faire un bilan critique des relations entre immigration, partis politiques et espace public. I 